\title{
Characterization of antigen and bacterial transport in the follicle-associated epithelium of human ileum
}

\author{
Åsa V Keita ${ }^{1}$, Elisabet Gullberg ${ }^{2}$, Ann-Charlott Ericson ${ }^{3}$, Sa’ad Y Salim ${ }^{1}$, Conny Wallon ${ }^{1}$, \\ Anders Kald ${ }^{1}$, Per Artursson ${ }^{2}$ and Johan D Söderholm ${ }^{1}$ \\ ${ }^{1}$ Department of Biomedicine and Surgery, Division of Surgery, University Hospital, Linköping, Sweden; \\ ${ }^{2}$ Department of Pharmacy, Uppsala University, BMC, Uppsala, Sweden and ${ }^{3}$ Division of Cell Biology, \\ Faculty of Health Sciences, University Hospital, Linköping, Sweden
}

\begin{abstract}
The follicle-associated epithelium (FAE), covering Peyer's patches, provides a route of entry for antigens and microorganisms. Animal studies showed enhanced antigen and bacterial uptake in FAE, but no study on barrier function of human FAE has been reported. Our aim was to characterize the normal barrier properties of human FAE. Specimens of normal ileum were taken from 30 patients with noninflammatory colonic disease. Villus epithelium (VE) and FAE were identified and mounted in Ussing chambers. Permeability to ${ }^{51} \mathrm{Cr}$-EDTA, transmucosal flux of the protein antigen, horseradish peroxidase (HRP), and transport of fluorescent Escherichia coli (chemically killed K-12 and live HB101) were measured. Uptake mechanisms were studied by confocal- and transmission electron microscopy, and by using pharmacological inhibitors in an in vitro coculture model of FAE and in human ileal FAE. HRP flux was substantially higher in FAE than in VE, and was reduced by an amiloride analog. Electron microscopy showed HRP-containing endosomes. Transport of $E$. coli K-12 and HB101 was also augmented in FAE and was confirmed by confocal microscopy. In vitro coculture experiments and electron microscopy revealed actin-dependent, mainly transcellular, uptake of $E$. coli K-12 into FAE. ${ }^{51} \mathrm{Cr}$-EDTA permeability was equal in FAE and VE. Augmented HRP flux and bacterial uptake but similar paracellular permeability, suggest functional variations of transcellular transport in the FAE. We show for the first time that FAE of human ileum is functionally distinct from regular VE, rendering the FAE more prone to bacterial-epithelial cell interactions and delivery of antigens to the mucosal immune system.

Laboratory Investigation (2006) 86, 504-516. doi:10.1038/labinvest.3700397; published online 13 February 2006
\end{abstract}

Keywords: E. coli; horseradish peroxidase; M cell; permeability; Peyer's patches

The epithelial mucosal surface lining the gastrointestinal tract has conflicting roles. At the same time it digests and absorbs nutrients and acts as a barrier to protect the host from passage of adhering molecules and pathogens for example bacteria, viruses and protozoa. ${ }^{1}$ In addition, it has to allow small amounts of molecules and pathogens to reach the underlying immune cells for immunosurveillence. From animal studies, it is known that this mainly takes place in specialized accumulations of lymphoid cells so called lymphoid follicles. Isolated lymphoid follicles are spread through out the human intestine, whereas the follicles in the distal

Correspondence: Dr JD Söderholm, MD, PhD, Department of Biomedicine and Surgery, Division of Surgery, University Hospital, SE-581 85 Linköping, Sweden.

E-mail johda@ibk.liu.se

Received 10 September 2005; revised 23 December 2005; accepted 10 January 2006; published online 13 February 2006 ileum are grouped in larger aggregates called Peyer's patches. ${ }^{1}$ The lymphoid follicles mainly contain B cells and small populations of follicular dendritic cells and are separated from each other by regions of $\mathrm{T}$ cells and interdigitating dendritic cells. ${ }^{2}$ The epithelium that covers the lymphoid follicles, the follicle-associated epithelium (FAE), differs from the surrounding epithelium. It has few or no goblet or enteroendocrine cells, low amount of hydrolases, and lacks the ability to transport protective IgA from the interstitium to the lumen, since the entire FAE lacks polymeric Ig receptors. ${ }^{2}$ These features together gives the FAE a biochemical face to the lumen that facilitates uptake of antigen and various microorganisms, for example Escherichia (E.) coli, Yersinia and Salmonella. ${ }^{3}$ The uptake is further promoted by the presence of microfold (M) cells which promote transport of antigens and pathogens to underlying immune cells. ${ }^{4,5}$ Unfortunately, the histochemical properties of FAE and microfold cell 
( $\mathrm{M}$ cells) vary according to species and location ${ }^{6}$ and yet no universal human M-cell marker has been established. ${ }^{7}$

Previous animal studies have examined uptake and transport of antigens and bacteria in FAE; $;^{5,8,9}$ however, to date there are no reports quantifying barrier function of human FAE. The main objective of the present study was, consequently, to characterize the barrier properties of human FAE and compare it with regular villus epithelium (VE). To fulfill this aim, we modified a technique ${ }^{10}$ for the identification of FAE in human intestinal tissue, and studied transmucosal passage of antigens and bacteria in ileal specimens collected during surgery or colonoscopy. Mechanisms of uptake and transport were studied by microscopy and by pharmacological inhibition studies in human FAE tissue, as well as in the in vitro lymphocyte-epithelial cell coculture model of human FAE initially described by Kerneís et al, ${ }^{11}$ and subsequently used by several groups to study FAE and M-cell function. ${ }^{12-18}$ Our findings show that human ileal FAE is not only structurally, but also functionally distinct from regular VE, with enhanced transport of antigens and bacteria into the underlying lymphoid tissue.

\section{Materials and methods}

\section{Patients and Ethics}

Specimens, taken from terminal ileum next to the ileocaecal valve, were obtained from 30 patients at the University Hospital of Linköping. The material included 19 normal ileal specimens taken during surgery for colonic cancer from 8 men and 11 women aged 74 years (range 47-85 years), and during colonoscopy from 11 healthy persons under surveillance for colonic polyps, nine men and two women aged 59 years (range 38-75 years). The colon cancer patients had no generalized disease and none had received preoperative chemo- or radiotherapy. The study was approved by the committee of human ethics, Linköping, and all subjects gave their informed consent.

\section{Identification of FAE}

Surgical specimens were, immediately after division of the ileocolic artery, put in ice-cold oxygenated Krebs buffer (115 mM NaCl, $1.25 \mathrm{mM} \mathrm{CaCl}_{2}, 1.2 \mathrm{mM}$ $\mathrm{MgCl}_{2}, 2 \mathrm{mM} \mathrm{KH}_{2} \mathrm{PO}_{4}$ and $25 \mathrm{mM} \mathrm{NaHCO}_{3}, \mathrm{pH}$ 7.35), macroscopically reviewed by a pathologist, and transported to the laboratory for experiments. While immersed in Krebs buffer, the specimens were stripped of external muscle and myenteric plexus. Stripped tissue was put with the mucosa up in a Petri dish and carefully stretched out with needles. For identification of FAE, we modified a technique previously described for post-mortem ileal tissue. ${ }^{10}$ The dish was placed on a horizontal X-ray view box
(Philips, Sweden) and by transillumination from below, regions of $\mathrm{VE}$ and FAE could be identified in a dissection microscope (Figure 1a). Biopsies, identified as VE or FAE with magnification endoscopy, were taken at colonoscopy with a biopsy forceps without a central lance. They were directly put in a dish with Krebs buffer, and epithelial type was further identified with dissection microscopy as for surgical tissue. Microscopy further ensured that only biopsies of high quality without squeeze effects were used. Following the Ussing experiments, histological assessment verified epithelial type in each chamber (Figure $1 \mathrm{~b}$ and $\mathrm{c}$ ). Two biopsies identified as FAE before the experiments turned out to be VE when judged microscopically. Another two FAE and VE specimens were excluded due to technical problems.

\section{Ussing Chamber Experiments}

Tissues of VE and FAE were mounted in modified Ussing chambers (Harvard apparatus Inc., Holliston, MA, USA). ${ }^{19}$ FAE segments were carefully adjusted so that the follicles covered the entire exposed tissue surface area of $4.9 \mathrm{~mm}^{2}$ for surgical specimens and $1.8 \mathrm{~mm}^{2}$ for biopsies. Mucosal compartments were filled with $1.5 \mathrm{ml}$ cold $10 \mathrm{mM}$ mannitol in Krebs buffer and the serosal compartments were filled with $10 \mathrm{mM}$ glucose in Krebs buffer. The chambers were kept at $37^{\circ} \mathrm{C}$ and continuously oxygenated, $95 \% \quad \mathrm{O}_{2} / 5 \% \quad \mathrm{CO}_{2}$ and circulated by gas flow. Before the experiments were started, tissues were equilibrated for $40 \mathrm{~min}$ in the chambers to achieve steady-state conditions in transepithelial potential difference (PD), with a replacement of $37^{\circ} \mathrm{C}$ mannitol or glucose buffer at $20 \mathrm{~min}$. The short-circuit current (Isc) and transepithelial resistance (TER) and PD were monitored using one pair of Ag/AgClelectrodes with agar-salt bridges and one pair of current-giving platinum electrodes. The chamber experiments were performed in open circuit conditions, with sampling of electrophysiology data every second min during the entire experimental period via LabVIEW software (LabVIEW, National Instruments, Solna Sweden). A four electrode system was used as previously described. ${ }^{20}$ One pair of Ag/ Ag-electrodes (Ref 201, Radiometer, Copenhagen, Denmark) with $3 \mathrm{M} \mathrm{NaCl} / 2 \%$ agar bridges was used for measurements of PD and one pair of platinum electrodes for current passage. Transepithelial potential difference, Isc and TER were obtained as described by Karlsson et $a .^{21}$ The electrodes were coupled to an external six channel electronic unit with a voltage controlled current source. Data sampling was computer controlled via an A/D D/A board (Lab NB, National Instruments, USA) by a program developed in Lab View (National Instruments, USA). Every second minute, direct pulses of $1.5,-1.5,3,-3$ and $0 \mu \mathrm{A}$ with duration of $235 \mathrm{~ms}$ were sent across the mucosal specimens and the 

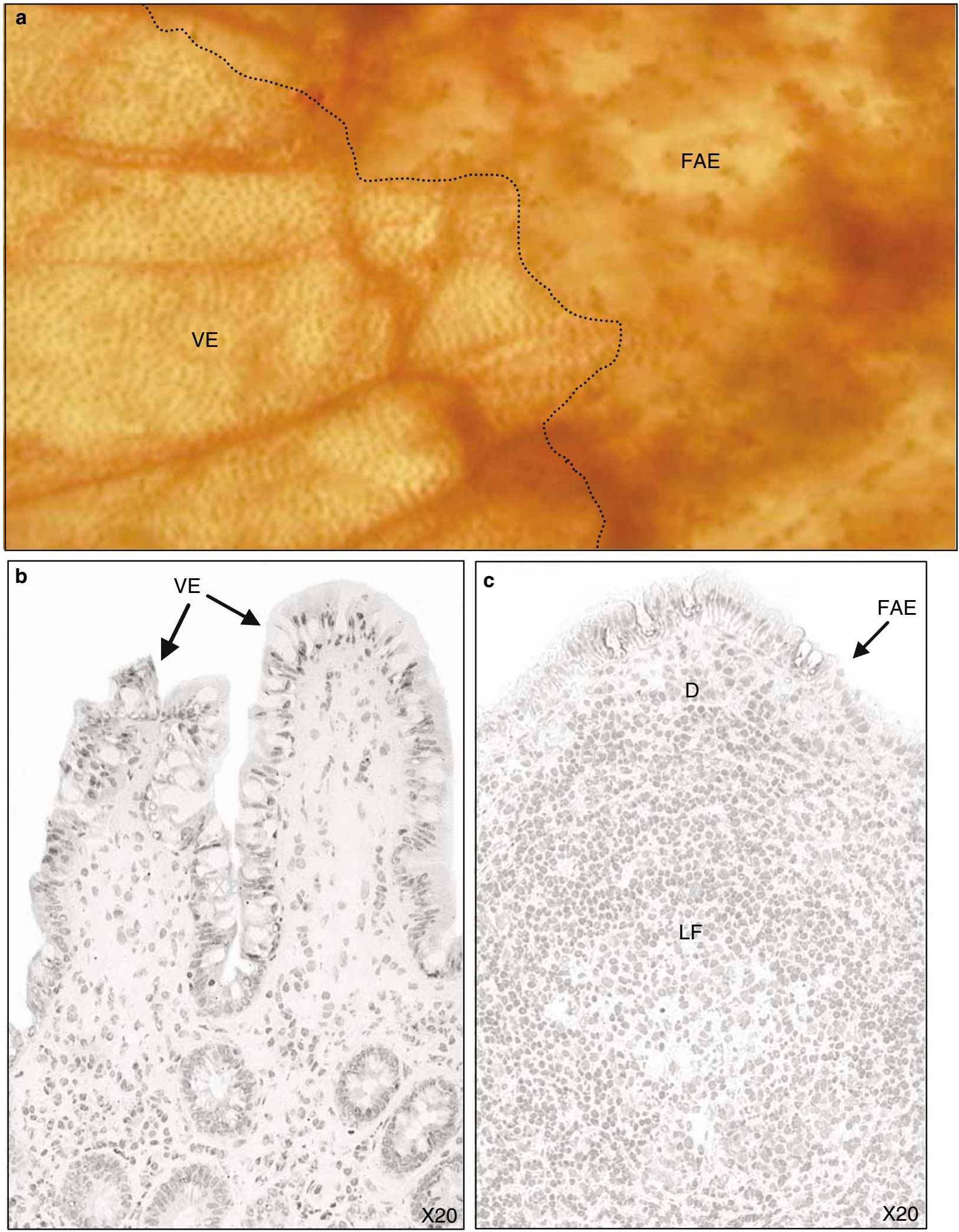

Figure 1 Identification of human follicle-associated epithelium (FAE) and villus epithelium (VE). (a) Identification of FAE and VE was performed in a dissection microscope by transillumination from below. The border between FAE and VE is indicated by a stitched line. The villi are seen as darker dots. Note the regular pattern of villi in close apposition in the VE compared to the more irregular pattern of multiple follicles surrounded by sparse villi, in FAE. (b) Histological assessment of VE, following Ussing chamber experiments. (c) Histological assessment of an ileal lymphoid follicle (LF) and the overlaying FAE, $\mathrm{D}=$ dome. 
voltage response was measured. In each measurement the mean voltage response of eight recordings was calculated. By this procedure, the influence of AC disturbances of $25-100 \mathrm{~Hz}$ were eliminated. A linear least-squares fit was performed of the current $(I)$-voltage $(U)$ pair relationship: $U=\mathrm{PD}+\mathrm{TER} \times I$. From the slope of the line, TER was obtained, and PD from the intersection of the voltage. Tissue conductance was then calculated by inverting the TER values. All parameters were calculated during the $30-90 \mathrm{~min}$ period.

\section{Macromolecular Permeability}

Two segments of VE and FAE from each of 14 patients (eight surgical specimens, six biopsies) were mounted in Ussing chambers. The $45 \mathrm{kDa}$ protein antigen horseradish peroxidase (HRP; type VI, Sigma Chemical Co., St Louis, MO, USA) was used as a marker of transcellular passage, whereas the inert probe ${ }^{51} \mathrm{Cr}-\mathrm{EDTA}$, (MW $384 \mathrm{D}$; Perkin-Elmer, Boston, MA, USA) was used as a paracellular probe. Horseradish peroxidase and ${ }^{51} \mathrm{Cr}$-EDTA were added to the mucosal side to a final concentration of $10^{-5} \mathrm{M}$ and $34 \mu \mathrm{C}_{\mathrm{i}} / \mathrm{ml}$, respectively. Serosal samples $(300 \mu \mathrm{l})$ were collected at $0,30,60$ and $90 \mathrm{~min}$ after start. An aliquot from each sample was saved for HRP analysis (see below) and the remainder was placed in a gamma-counter (1282 Compugamma, LKB, Bromma, Sweden) for ${ }^{51}$ Cr-EDTA measurements. Permeability was calculated during the $30-90 \mathrm{~min}$ period for both markers. ${ }^{51} \mathrm{Cr}$-EDTA permeability was given as $P_{\text {app }}$ (apparent permeability coefficient; $\left.\mathrm{cm} / \mathrm{s} \times 10^{-6}\right)$, and HRP permeability presented as transmucosal flux $\left(\mathrm{pmol} / \mathrm{h} / \mathrm{cm}^{2}\right)$.

\section{HRP analysis}

Horseradish peroxidase was measured using the QuantaBlu $^{\mathrm{TM}}$ Fluorgenic Peroxidase Substrate Kit (Pierce, Rockford, USA) according to a protocol developed at our laboratory. ${ }^{8}$ In brief, serosal samples were diluted and transferred to microtitre plates. QuantaBlu ${ }^{\mathrm{TM}}$ Working Solution was added and plates were incubated at 300 r.p.m. at room temperature. After exactly $30 \mathrm{~min}$, QuantaBlu ${ }^{\mathrm{TM}}$ Stop Solution was added and absorbances of the reaction products were measured at excitation wavelength $325 \mathrm{~nm}$ and emission wavelength $420 \mathrm{~nm}$ using a fluorimeter (Cary Eclipse, Varian, Victoria, Australia). Blanks were included in each analysis and all samples were run in duplicate and measured against a standard curve.

\section{Transmission electron microscopy}

To determine the passage routes for HRP, two VE and two FAE segments, each from three patients, were mounted and exposed to $10^{-5} \mathrm{M}$ HRP on the mucosal side for five and $15 \mathrm{~min}$, respectively. Segments were fixed in situ in the chambers with $2 \%$ glutaraldehyde for $2 \mathrm{~h}$ and then carefully transferred to $0.1 \mathrm{M}$ sodium cacodylate buffer, $\mathrm{pH}$ 7.4. After washing in Tris buffer, segments were incubated with $0.6 \mathrm{mg} / \mathrm{ml} \mathrm{DAB}+3 \% \quad \mathrm{H}_{2} \mathrm{O}_{2}$ for $30 \mathrm{~min}$, and transferred to cacodylate buffer with $1 \%$ osmium (1:1). After $1 \mathrm{~h}$, segments were washed in cacodylate buffer, dehydrated and embedded in Epon (TAAB 812, Analytical standards, Gothenburg, Sweden). Sections were stained with lead citrate and uranyl acetate and examined by transmission electron microscopy (JEM-1230, JEOL Sollentuna, Sweden).

\section{Passage of Chemically Killed E. coli K-12}

Two to three FAE and VE segments from each of 10 patients (six surgical specimens, four biopsies) were mounted in Ussing chambers. After equilibration, chemically killed fluorescein isothiocyanate (FITC)conjugated E. coli K-12 BioParticles (Molecular Probes, Leiden, The Netherlands) were added to the mucosal side to a final concentration of $1.0 \times 10^{8} \mathrm{CFU} / \mathrm{ml}$. These bacteria are killed with paraformaldehyde which stops their reproduction but retains antigenicity. ${ }^{22}$ After 90 and $120 \mathrm{~min}$, serosal compartments were collected and analyzed at $488 \mathrm{~nm}$ in a fluorimeter (Cary Eclipse, Varian) where 1 unit refers to $1.5 \times 10^{6} \mathrm{CFU} / \mathrm{ml}$.

\section{Confocal laser scanning microscopy}

At 90 and $120 \mathrm{~min}$, segments were fixed in situ in the chambers with $4 \%$ formaldehyde in PBS; $\mathrm{pH} 7.4$, for $2 \mathrm{~h}$ and then carefully rinsed in PBS and incubated with $10 \mu \mathrm{g} / \mathrm{ml}$ Alexa Flour 594 phalloidin (Molecular Probes) to visualize F-actin. After $30 \mathrm{~min}$, tissues were rinsed in PBS, mounted in antifading Fluorescent Mounting Medium (DakoCytomation, CA, USA) and examined in a Nikon Eclipse E600W confocal laser scanning microscope (Nikon, NY, USA) using Nikon EZ-C1 software, with a $60 \times$ oil-immersion objective. An ion laser permitted simultaneous excitation wavelengths of $488 \mathrm{~nm}$ for FITC-labeled E. coli and $594 \mathrm{~nm}$ for Alexa-labeled phalloidin.

\section{Transmission electron microscopy}

To determine the passage routes for $E$. coli K-12, 3 FAE segments, each from three patients, were mounted and exposed to $1.0 \times 10^{8}$ E. coli K-12 on the mucosal side for 10 and $20 \mathrm{~min}$, respectively. Segments were fixed in situ in the chambers with $2 \%$ glutaraldehyde for $2 \mathrm{~h}$ and then processed as described above for electron microscopy studies of HRP passage routes, except for incubation with DAB.

\section{Passage of Live E. coli HB101}

In addition to studies with dead E. coli K-12, ileal tissue from seven patients (four surgical specimens, three biopsies) were used for studies with live green 
fluorescent protein-incorporated E. coli HB101 (One Shot $^{\circledR}$ TOP10 Competent Cells, Invitrogen, CA, USA). The transfection was performed by adding $5 \mu \mathrm{l}$ of plasmid enhanced green fluorescent protein 1:100 to $50 \mu \mathrm{l}$ of competent HB101. The mixture was gently shaken and incubated on ice for $30 \mathrm{~min}$ followed by heat shock at $40^{\circ} \mathrm{C}$ for $90 \mathrm{~s}$. After addition of $450 \mu \mathrm{l}$ SOC medium, bacteria were incubated at $37^{\circ} \mathrm{C}, 200$ r.p.m., for $1 \mathrm{~h}$ and then plated on $\mathrm{LB}+$ ampicillin agar plate to grow at $37^{\circ} \mathrm{C}$.

Two to three FAE and VE segments from each patient were mounted in Ussing chambers, $1.0 \times 10^{8} \mathrm{CFU} / \mathrm{ml}$ of $E$. coli HB101 were added, and tissues were further processed for quantification and confocal microscopy as described for experiments with $\mathrm{K}-12$.

Effect of E. coli $K-12$ and HB101 on ${ }^{51} \mathrm{Cr}$-EDTA flux FAE and VE segments from five patients were mounted in Ussing chambers. Following system equilibration (as previously described), ${ }^{51} \mathrm{Cr}$-EDTA was added to the mucosal compartment at a final concentration of $34 \mu \mathrm{C}_{\mathrm{i}} / \mathrm{ml}$ with or without addition of the chemically killed FITC-conjugated E. coli K-12 or GFP-incorporated E. coli HB101 at a concentration of $1 \times 10^{8} \mathrm{CFU} / \mathrm{ml}$, respectively, as described above. Serosal samples were collected every $30 \mathrm{~min}$ for $2 \mathrm{~h}$. The paracellular flux of ${ }^{51} \mathrm{Cr}$-EDTA was measured by gamma counting and the values are presented as percent of control (nonexposed tissues).

\section{In Vitro Studies of Uptake Mechanisms}

\section{Coculture model}

To further study the mechanisms behind the increased uptake of HRP and bacteria in human FAE, the in vitro coculture model of FAE was used. In a paper by Kerneís et $a l^{11}$ it was shown that coculture of Peyer's patch lymphocytes and intestinal epithelial cells may trigger conversion of the epithelial cells to $\mathrm{M}$ cells. This model and variants of it have been used to study M-cell function, ${ }^{12-17}$ and by using our previously established modification $^{18}$ of the original model, mechanisms of antigen and bacterial uptake could be studied. Briefly, intestinal epithelial Caco-2 cells were grown on Matrigel $^{\text {TM }}$ (Becton Dickinson, USA) coated polycarbonate filters (Costar, Baedvenhorp, NL, USA) with a mean pore size of $3.0 \mu \mathrm{m}$. The model FAE was obtained by adding $5 \times 10^{5}$ Raji B cells (ATCC, MD, USA) resuspended in Dulbecco's Modified Eagle Medium to the basolateral chamber of 14-day-old Caco-2 cell monolayers. The coculture was then maintained for $4-5$ days before onset of experiments. Corresponding monocultures of Caco-2 cells on matched filter supports served as controls. Before and after transport experiments, TER was measured to check cell monolayer integrity, and only filters with maintained integrity were used. To verify model FAE function, transcytosis of $0.2 \mu \mathrm{m}$ polystyrene beads was studied for each batch of cells.

\section{Experimental protocol}

All experiments were performed in Hank's Balanced Salt Solution (HBSS) with addition of $25 \mathrm{mM}$ Hepes buffer, pH 7.4. Before experiments, the cell monolayers were incubated with either the amiloride analog 5-( $N$-ethyl- $N$-isopropyl)-amiloride (EIPA), $(100 \mu \mathrm{M})$, an inhibitor of the apical membrane $\mathrm{Na}+/ \mathrm{H}+$ exchanger, which has been used as an inhibitor of macropinocytosis, ${ }^{23,24}$ the F-actin polymerization inhibitor cytochalasin $\mathrm{D}(0.1 \mu \mathrm{M})$, microtubule transport modulator colchicine $(10 \mu \mathrm{M})$ or HBSS (control) at $37^{\circ} \mathrm{C}$ for $30 \mathrm{~min}$, according to established protocols. ${ }^{12,25}$ Transepithelial resistance was measured before and after incubation. For HRP studies, $10^{-5} \mathrm{M}$ HRP, with or without EIPA, was added to the apical side of the cells, samples were withdrawn at regular time intervals, stored at $-20^{\circ} \mathrm{C}$ and analyzed as described for human tissue. E. coli $\mathrm{K}-12$ experiments, $1.0 \times 10^{8} \mathrm{CFU} / \mathrm{ml}$ were added to the apical side, with or without inhibitors. After $20 \mathrm{~min}$, the cell monolayers were washed several times in HBSS to remove loosely adherent bacteria, fixed in $4 \%$ formaldehyde for $10 \mathrm{~min}$, washed in HBSS and stored for confocal microscopy of internalized bacteria. Bacterial transport could not be studied in this model system since studies of E. coli K-12 transport through empty cell culture filter supports revealed that the bacteria were too large to pass through the pores.

\section{Quantification of bacterial transport}

The number of surface-bound, intracellularly and paracellularly located $E$. coli was quantified in a confocal laser scanning microscope (Leica TCS SP2, Germany) by counting the number of bacteria in six predefined areas of each cell monolayer. In order not to affect the location of bacteria within the cell monolayers, the fixed cells were not permeabilized or stained before analysis, but simply cut out of the filter holders and mounted on glass slides. Excitation with an ion laser at $488 \mathrm{~nm}$ allowed simultaneous reflection of the cell monolayers and detection of the FITC-labeled E. coli (emittance detected at $488 \mathrm{~nm}$ and above $530 \mathrm{~nm}$, respectively). In order to visualize and count bacteria at different locations in the cell monolayer, stacks of images were collected by scanning the entire height of the cell monolayer in the predefined areas of each filter, each containing approximately 400 cells. Projections of these stacks in the $x-z$ and $y-z$ dimension with LCS Lite ${ }^{\mathrm{TM}}$ software (Leica, Germany) permitted visualization of bacteria throughout the cell monolayer. The numbers of surface-bound, intracellular and paracellular E. coli in the six areas were summarized and the mean number of E. coli $/ \mathrm{mm}^{2}$ was calculated for each treatment. Three to six filters were used for analysis of each treatment. 


\section{Inhibition Studies of HRP in Human FAE}

Subsequent to the studies in the in vitro coculture model of FAE showing inhibition of HRP uptake by EIPA (see further above under in vitro studies), confirmatory studies were performed in human tissue FAE. Surgical specimens of ileal mucosal FAE and VE from four patients were mounted in Ussing chambers, as described above. Following 20 min of equilibration, EIPA $(100 \mu \mathrm{M})$ or vehicle was added to the mucosal side of specimens of each epithelial type. After another $20 \mathrm{~min}$, HRP $\left(10^{-5} \mathrm{M}\right)$ and ${ }^{51} \mathrm{Cr}$-EDTA $(34 \mu \mathrm{Ci} / \mathrm{ml})$ were added to the chambers (two EIPA and two controls of each epithelial type, respectively, in each patient). Samples were withdrawn every $30 \mathrm{~min}$ for $2 \mathrm{~h}$ and the passage of ${ }^{51} \mathrm{Cr}$-EDTA and HRP were analyzed as described above.

\section{Statistics}

Values are given as median (25-75th interquartile range). Comparisons between two groups were performed with Mann-Whitney $U$ test or Wilcoxon signed rank test when applicable. Differences with $P<0.05$ were considered significant.

\section{Results}

Equal Permeability in Surgical Specimens and Biopsies

Our group previously showed that permeability was equal in surgical specimens and biopsies of human colon $^{26}$ and initially we wanted to confirm these findings in human ileal mucosa. After $40 \mathrm{~min}$ of equilibration, PD was stable in all tissues. The active net ion transport, assessed as Isc, was similar in surgical specimens and biopsies in both VE and FAE (Table 1). On the other hand, the conductance was lower in surgical specimens compared to biopsies in both tissue types, $P<0.001$. This is in line with previous results from human $\operatorname{colon}^{26}$ and probably refers to the thicker subepithelial layer in surgical specimens, giving higher total resistance recordings. However, it could also refer to differences in the mounting process with the influence of stretching the epithelium in surgical specimens and a higher risk of edge damage in biopsy chambers. There were no significant differences between surgical specimens and biopsies in permeability to ${ }^{51} \mathrm{Cr}$ - EDTA, or to HRP (Table 1). Moreover, fluorimetric measurements showed no significant differences in E. coli K-12 and HB101 passage between surgical specimens and biopsies, neither in FAE nor in VE (Table 1). As there were no significant differences in ${ }^{51} \mathrm{Cr}-\mathrm{EDTA}$, HRP or bacterial passage between surgical specimens and biopsies, the two techniques can be considered equal regarding studies of macromolecular permeability and bacterial uptake. Therefore, the flux data for surgical specimens and biopsies were pooled.

\section{Enhanced Transcellular Transport of HRP in FAE}

\section{Transport quantification}

There was no difference in permeability to the paracellular probe, ${ }^{51} \mathrm{Cr}$-EDTA, between FAE and VE (1.6 (1.1-1.9) vs $1.0(0.6-1.5) \mathrm{cm} / \mathrm{s} \times 10^{-6}$; Figure 2a). On the other hand, the transmucosal transport of HRP was substantially higher in FAE compared to VE (36.0 (31.5-67.0) vs 6.3 (3.1-16.3) $\mathrm{pmol} / \mathrm{h} / \mathrm{cm}^{2}$, $P<0.001$ ) (Figure 2b).

\section{Transport routes}

Electron microscopy showed an increased number of vacuoles within the FAE enterocytes and endosomal HRP-uptake was more frequently found within the FAE compared to VE (Figure 3a and b). No HRP was found in the paracellular spaces neither in FAE nor in VE, suggesting mainly transcellular uptake of HRP. The ultrastructural examination of FAE further revealed a mucosa with lymphocytes close to the epithelial cells and lymphocytes in close contact with HRP-containing

Table 1 Comparisons of electrophysiology and permeability between surgical specimens and biopsies

\begin{tabular}{|c|c|c|c|c|}
\hline Measured parameter & VE surgery & VE biopsy & FAE surgery & FAE biopsy \\
\hline$I_{\mathrm{sc}}\left(\mu \mathrm{A} / \mathrm{cm}^{2}\right)$ & $10.6(4.4-15.2)$ & $6.1(3.3-18.8)$ & $8.7(4.8-9.9)$ & $11.1(7.8-13.8)$ \\
\hline $\mathrm{G}\left(\mathrm{ms} / \mathrm{cm}^{2}\right)$ & $13.7(12.1-15.1)$ & $35.1(32.4-46.1)^{*}$ & $13.0(11.3-14.8)$ & $27.9(24.4-39.8) * *$ \\
\hline${ }^{51} \mathrm{Cr}-\mathrm{EDTA}\left(\mathrm{cm} / \mathrm{s} \times 10^{-6}\right)$ & $0.9(0.4-1.4)$ & $1.2(0.8-1.8)$ & $1.6(0.8-1.9)$ & $1.6(0.8-1.9)$ \\
\hline $\mathrm{HRP}\left(\mathrm{pmol} / \mathrm{h} / \mathrm{cm}^{2}\right)$ & $8.7(4.7-16.8)$ & $4.2(1.7-8.7)$ & $39.0(32.0-81.0)$ & $32.0(14.0-53.8)$ \\
\hline E. coli K-12 (units, $90 \mathrm{~min}$ ) & $0.4(0.1-0.8)$ & $0.4(0.2-1.3)$ & $1.0(0.9-1.5)$ & $1.0(0.8-2.7)$ \\
\hline E. coli K-12 (units, $120 \mathrm{~min}$ ) & $0.7(0.4-1.6)$ & $1.1(1.0-1.4)$ & $2.7(2.5-3.2)$ & $4.0(3.1-4.2)$ \\
\hline E. coli HB101 (units, $90 \mathrm{~min}$ ) & $3.2(2.5-3.8)$ & $2.9(2.4-3.3)$ & $4.7(4.0-4.9)$ & $4.6(4.1-5.2)$ \\
\hline E. coli HB101 (units, $120 \mathrm{~min}$ ) & $3.1(2.4-3.9)$ & $2.1(1.5-3.0)$ & $4.8(4.5-5.0)$ & $4.0(3.1-4.8)$ \\
\hline
\end{tabular}

Normal human ileum, taken during surgery or colonoscopy, was mounted in Ussing chambers for permeability measurements.

$\mathrm{VE}=$ villus epithelium; FAE $=$ follicle-associated epithelium; $I_{\mathrm{sc}}=$ short-circuit current; $\mathrm{G}=$ conductance; HRP $=$ horseradish peroxidase.

Values are given as median (25-75th interquartile range) and comparisons between two groups were performed with Mann-Whitney $U$ test.

* $=P<0.001$ compared to VE surgery.

$* *=P<0.001$ compared to FAE surgery. 
endosomes (Figure 3c and d). M cells, identified according to established definitions ${ }^{5,6}$ were observed within the FAE (Figure 3e).

a

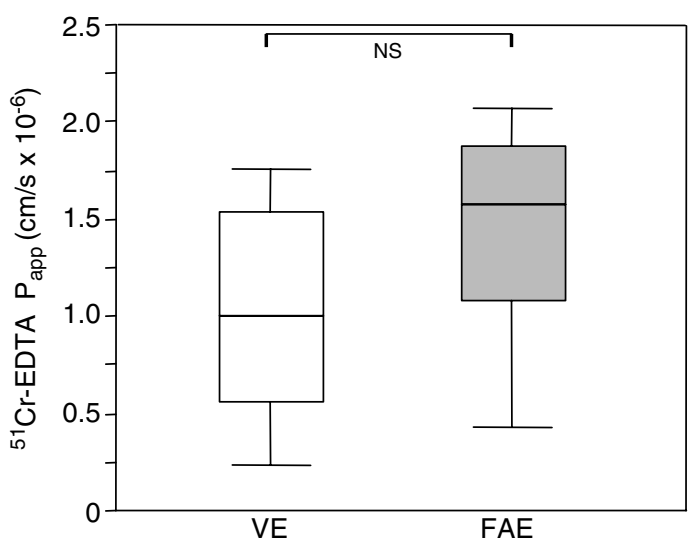

b
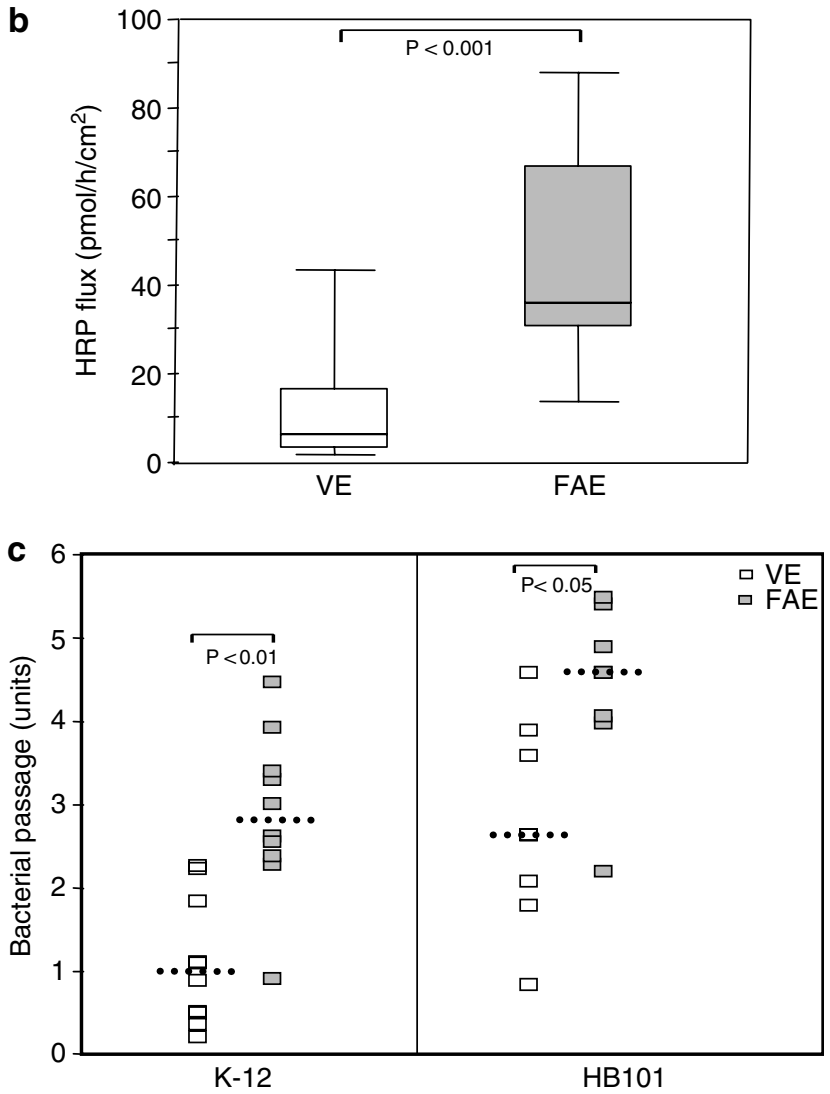

Figure 2 Mucosal permeability in human ileum. Segments of normal human villus epithelium (VE) and follicle-associated epithelium (FAE) were mounted in Ussing chambers. Values are presented as median (25-75th interquartile range) and comparisons were performed with Mann-Whitney $U$ test $(\mathbf{a}-\mathbf{b})$ or Wilcoxon signed rank test (c), $n=$ number of patients. (a) There was no difference between VE and FAE in permeability to the paracellular marker ${ }^{51} \mathrm{Cr}$-EDTA $(n=14)$. (b) A higher permeability to the transcellular marker horseradish peroxidase (HRP) was seen in FAE compared to VE $(n=14)$. (c) Permeability to chemically killed E. coli $\mathrm{K}-12(n=10)$ or live E. coli HB101 $(n=7)$ was increased in FAE compared to VE after $120 \mathrm{~min}$. The squares represent the values of each patient, and the dotted line represents the median value of the respective epithelial type, 1 unit $=1.5 \times 10^{6} \mathrm{CFU} / \mathrm{ml}$

\section{Transport mechanisms}

Studies of HRP transport in the cell co-culture model confirmed an increased transport of HRP in FAE. The model FAE showed a threefold increased HRP flux compared to Caco-2 (37.5 (28.8-56.1) vs $\left.13.0(11.9-15.7) \mathrm{cm} / \mathrm{s} \times 10^{-9}, P<0.05\right)$ (Figure 4a). The transport was inhibited by EIPA in both model FAE (37.5 (26.5-60.6) vs 21.1 (20.4-23.4), $P<0.05)$ and Caco-2 (13.0 (11.9-15.7) vs 10.5 (8.9-11.1), $P<0.05)$. The mean TER-values of the cell monolayers were $279 \pm 64 \Omega \mathrm{cm}^{2}$. Transepithelial resistance values of $200 \Omega \mathrm{cm}^{2}$ have previously been shown to represent Caco-2 cell monolayers with an uncompromised integrity. ${ }^{27}$ The TER was very little affected by incubation with EIPA $(102.1 \pm 0.05 \%$ of initial value).

In addition, HRP flux in human ileal FAE was inhibited by EIPA in a similar pattern, although this did not reach statistical significance (Figure 4b). ${ }^{51}$ Cr-EDTA permeability (FAE: control $1.2(1.0-1.4)$ vs EIPA $1.6(1.2-1.7) \mathrm{cm} / \mathrm{s} \times 10^{-6}$; VE: control 0.9 $(0.8-1.2)$ vs EIPA $\left.1.1(0.9-1.4) \mathrm{cm} / \mathrm{s} \times 10^{-6}\right)$ and conductance $(96.9 \pm 0.05$ and $105.3 \pm 0.03 \%$ of control at $60 \mathrm{~min}$, respectively) were not affected by EIPA exposure to human tissue samples.

\section{Transmucosal Passage of Non-Pathogenic Bacteria was Transcellular and Actin-Dependent in FAE}

\section{Human tissue}

At $90 \mathrm{~min}$, fluorimetric measurements showed an increased passage of $E$. coli $\mathrm{K}-12$ in FAE compared to VE (1.0 (0.9-1.7) vs $0.4(0.1-0.9)$ units, $P<0.05)$ while the passage of live E. coli HB101 was only slightly higher in FAE (4.7 (3.8-5.3) vs 3.2 (2.3-3.8), $P=0.1)$. However, at $120 \mathrm{~min}$, the passage was significantly increased for both $E$. coli K-12 $(2.9$ (2.5-3.4) vs $1.0(0.5-1.7), P<0.01)$ and HB101 (4.6 (4.0-5.2) vs $2.7(1.9-3.8), P<0.05)$ (Figure 2c). In all cases, bacterial passage was higher in FAE compared to VE specimens from the same patient.

The bacterial uptake was confirmed by microscopy. Transmission electron microscopy demonstrated several bacteria attached to the epithelial surface and transcellular uptake with actin accumu-

Figure 3 Electron photomicrographs of human ileum. Segments of follicle-associated epithelium (FAE) and villus epithelium were mounted in Ussing chambers. Horseradish peroxidase (HRP) was added to the mucosal side and tissues were taken out after 15 min. (a) The FAE mucosa contained a high number of vacuoles and HRP-containing endosomes (arrows). (b) The villus epithelium showed normal appearance with tight regular microvilli and a dense cytoplasm, arrow indicates HRP uptake. (c) FAE demonstrating a mucosa with lymphocytes close to the epithelial cells. Frame indicates the close contact between a lymphocyte (L) and an HRP-containing endosome (arrow). (d) Magnification of the frame in (c). (e) An example of an M cell (M) with an adjacent enterocyte (E) found within the FAE. The M cell was identified according to established definitions for example irregular, short microvilli, prominent vesicles and intraepithelial pockets containing lymphocytes (L). ${ }^{5,6}$ Arrows indicate HRP-uptake. 

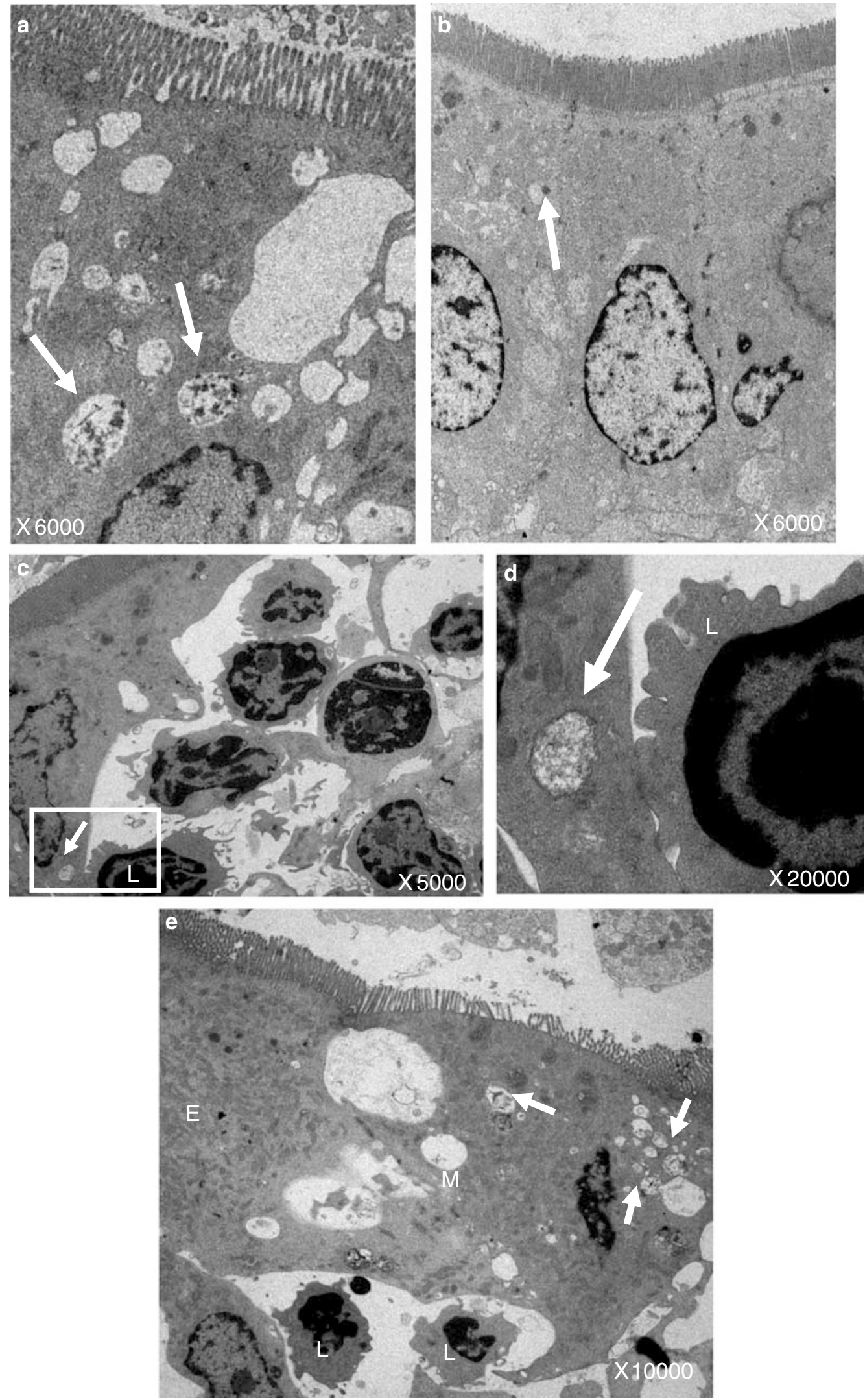


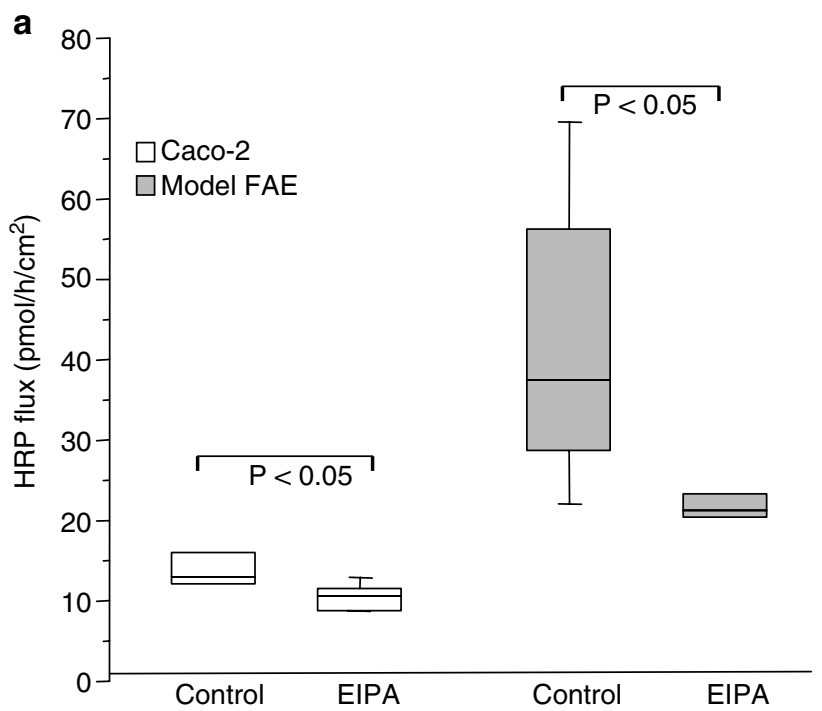

b

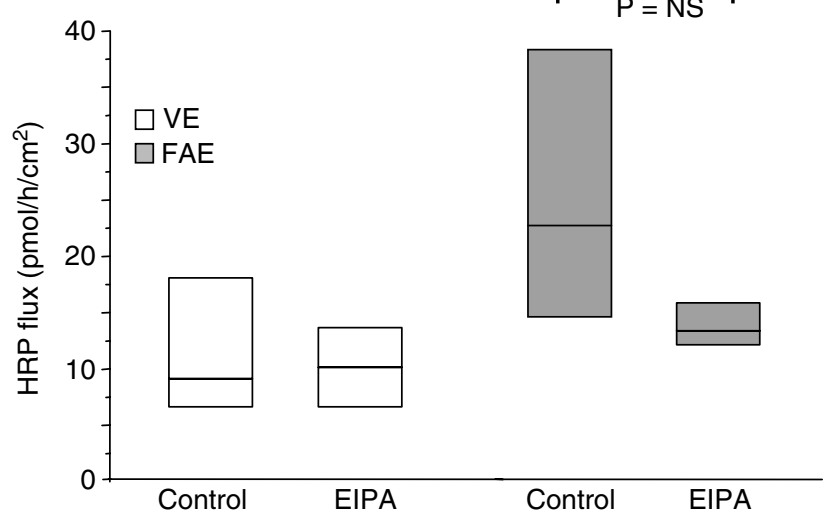

Figure 4 Transport of horseradish peroxidase (HRP) across human follicle-associated epithelium (FAE). (a) Inhibition of transepithelial HRP flux. The in vitro coculture model of FAE and Caco-2 epithelium were preincubated with the macropinocytosis inhibitor, 5-( $N$-ethyl- $N$-isopropyl) amiloride (EIPA), or buffer control ( $n=5$ filters in each group). HRP, with or without EIPA, was added to the apical side and samples were taken from the basolateral side at regular time intervals. The HRP transport was significantly higher across the model FAE than the Caco-2 epithelium and could be inhibited by EIPA. (b) Inhibition of transmucosal HRP flux in human ileal FAE. Samples of FAE and villus epithelium (six samples of each from four patients) were exposed to EIPA or control buffer. Lower HRP flux was seen in EIPA-exposed FAE tissues. Values are presented as median (2575th interquartile range). Comparisons were performed with Mann-Whitney $U$ test, NS $=$ nonsignificant.

lation at the contact sites (Figure $5 \mathrm{a}$ and b). Similarly, confocal microscopy showed fluorescent bacteria on the surface of the epithelium in both FAE and VE; however, the amount of attached bacteria was higher in FAE (data not shown). Transepithelial passage of E. coli K-12 and HB101 is illustrated in Figure 5c and d, showing mainly intracellular epithelial localization, and further transport into immune cells in the subepithelial dome area.
Paracellular permeability was not affected by exposure to $E$. Coli, neither assessed as ${ }^{51} \mathrm{Cr}$-EDTA flux (FAE: K-12: 111 (86-136)\%; HB101:100 (90$110) \%$ of control nonexposed tissues; VE: K-12: 113 (78-167); HB101:125 (90-150)\% of control), nor as mucosal conductance ((FAE: 103 (96-108)\%; VE:106 (99-111)\% of control nonexposed tissues after 60 min exposure).

\section{Coculture model of FAE}

In agreement with the results on tissue FAE and VE, confocal microscopy revealed that the number of internalized E. coli K-12 was greater in the model FAE than in the Caco-2 epithelium (304 (259-367) vs 107 (83-215) E. coli $/ \mathrm{mm}^{2}, P<0.05$ ) (Figure 6). In the model FAE, cytochalasin D significantly inhibited the number of surface-bound bacteria (60 (29-81) vs 107 (85-139) E. coli/2400 epithelial cells; $P<0.05)$ as well as the internalization of bacteria into enterocytes (133 (80-207) vs 304 (259-367) E. coli $/ \mathrm{mm}^{2}, P<0.05$ ) (Figure 6). Numerically, a similar pattern was seen in the Caco-2 epithelium, however, the inhibitory effects were not significant $(P=0.4)$. Colchicine had no significant inhibitory effect on bacterial internalization. Confocal microscopy further revealed that bacteria were only rarely found in the paracellular spaces in either model FAE or Caco-2. Surface-bound bacteria were found in all cell monolayers regardless of treatment. The TER of the monolayers was very little affected by incubation with colchicine $(95.5 \pm 0.01)$ or cytochalasin D $(99.0 \pm 0.01)$ compared with buffer controls $(100.9 \pm 0.02)$.

\section{Discussion}

To our knowledge no permeability studies on human FAE have previously been reported. Consequently, this study was designed to characterize the uptake properties of normal human FAE and compare it with regular VE. In the FAE we found a high transmucosal flux of the protein antigen, HRP, whereas ${ }^{51} \mathrm{Cr}$-EDTA flux and conductance did not significantly differ between VE and FAE. These findings are in line with our previous studies in rat $\mathrm{FAE}^{8}{ }^{8}$ and point to an enhanced uptake of antigens in the human FAE compared with VE, but equal paracellular permeability. Analogous to the enhanced antigen uptake, a notably higher transmucosal passage of both chemically killed K-12 and live HB101 E. coli was found, which further implies that the human FAE is prone to uptake and transport of antigens and bacteria.

Our studies with pharmacological inhibitors and microscopy suggest that the transepithelial uptake of antigens and bacteria in the FAE is mainly transcellular. The amiloride analog, EIPA, which inhibits sodium-hydrogen exchange and thereby reduces a driving force for uptake through the apical membrane $(\mathrm{H}+$ electrochemical gradient $),{ }^{28}$ has 

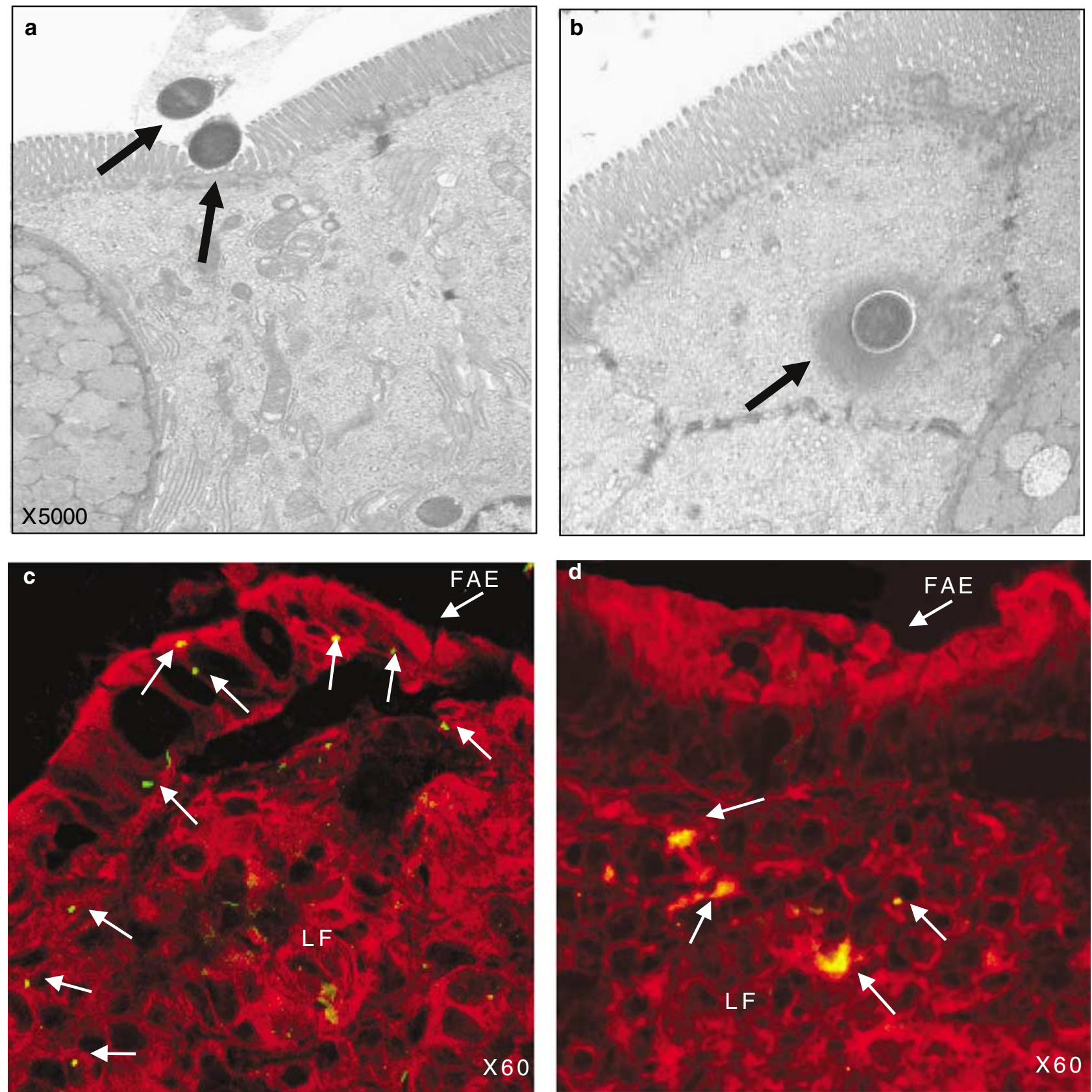

Figure 5 Bacterial passage in human ileum. Normal villus epithelium (VE) and follicle-associated epithelium (FAE) from the ileum of 10 patients were mounted in Ussing chambers and passage of chemically killed E. coli K-12 and live HB101 was studied with confocal and transmission electron microscopy. (a) Electron photomicrograph showing E. coli K-12 (arrows) attaching to the epithelial surface, with disappearance of microvilli, after $10 \mathrm{~min}$. (b) Internalized E. coli K-12 seen after $20 \mathrm{~min}$. Note the actin accumulation at the contact sites (arrow). (c) Epithelial uptake of E. coli K-12 into FAE, showing mainly intracellular localization of bacteria (arrows). (d) Uptake of live E. coli HB101 (arrows) into the subepithelial dome area of FAE. Red=Alexa Flour 594 phalloidin, green =FITC-labeled E. coli K-12 or GFP-incorporated E. coli HB101, LF = lymphoid follicle.

been used as a pharmacological inhibitor of macropinocytosis. ${ }^{24}$ Previous studies have shown that amiloride and its analogs inhibits pinocytosis of HRP, but not receptor-mediated uptake or uptake via clathrin-coated pits. ${ }^{29,30}$ In our experiments, EIPA reduced the internalization and transport of HRP, in the coculture model as well as in human FAE, without affecting paracellular permeability. Ultra- structural studies corroborated the functional data by showing transcellular endosomal uptake of HRP. This suggests mainly transcytotic mechanisms for the enhanced transmucosal HRP flux in the human ileal FAE. Further, studies with E. coli K-12 in the model FAE revealed that when adding low concentrations of cytochalasin $\mathrm{D}$, the amount of internalized bacteria was decreased, suggesting that E. coli 


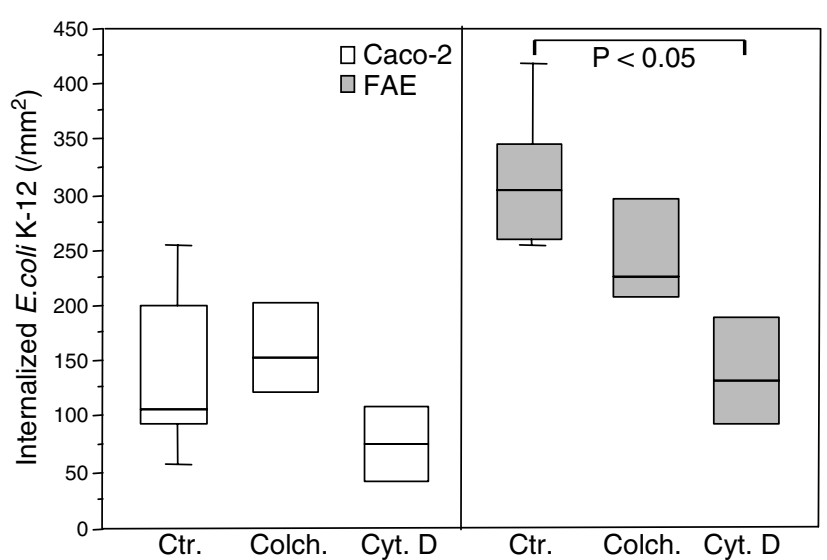

Figure 6 Quantification of internalized E. coli K-12 in model FAE and Caco-2 cell monolayers. The quantification was performed in the presence of HBSS (Ctr.), colchicine (Colch.) or cytochalasin D (Cyt. D). The cell monolayers were incubated with E. coli K-12, with or without inhibitor. The number of intracellular E. coli $/ \mathrm{mm}^{2}$ was counted in a confocal microscope, using LCS software ${ }^{\mathrm{TM}}$. The cells and filter were detected by direct reflection (magenta), the FITC-labeled bacteria (green) by excitation at $488 \mathrm{~nm}$. E. coli K-12 internalization was increased in model FAE compared to Caco-2 cell monolayers. In the model FAE, the internalization of bacteria was inhibited by cytochalasin. Values are presented as median (25-75th interquartile range) and comparisons were performed with Mann-Whitney $U$ test.

$\mathrm{K}-12$ is taken up via an actin-mediated transcellular route in FAE. This is well in line with recent data on uptake of nonpathogenic E. coli in porcine FAE. ${ }^{31}$ In contrast, colchicine had no significant effect on bacterial internalization, which probably refers to the fact that it blocks microtubule-dependent transcytosis but not the actin-dependent uptake into the enterocytes. $^{32}$ Electron microscopy demonstrated bacterial uptake with actin accumulation at the apical membrane contact sites, and confocal microscopy showing the majority of bacteria within epithelial cells. On the other hand, an indirect role for the paracellular pathway is possible, as suggested by the different expression of tight junction proteins found in mouse $\mathrm{FAE},{ }^{33,34}$ especially in disease states, such as intestinal inflammation. For example, several E. coli strains have been shown to affect the paracellular pathway in intestinal epithelia. ${ }^{35}$ Our data do not, however, give any suggestion of permeability alterations by the nonpathogenic E. coli strains used in the present study, which is in line with previous observations using these strains. ${ }^{36}$ The similar pattern induced by the pharmacological inhibitors in the Caco-2 epithelium may suggest that the same uptake mechanisms are present in FAE and VE, although upregulated in FAE.

The enhanced permeability in FAE tissue might also refer to the presence of $\mathrm{M}$ cells that facilitate luminal uptake of antigens and bacteria. ${ }^{2,37} \mathrm{M}$ cells constitute approximately $10 \%$ of the FAE, however, this number can be increased during intestinal inflammation. ${ }^{38,39} \mathrm{M}$ cells lack a developed micro- villus border and glycocalyx coat, which facilitates access for luminal pathogens and thereby the uptake increases. $^{2,37}$ There are large differences between different species regarding markers for $\mathrm{M}$ cells. ${ }^{6}$ For example, markers have been identified for pig, rabbit and mouse, ${ }^{7}$ however, there is today no universal human M-cell marker, which hampers the possibility to elucidate the actual role of $\mathrm{M}$ cells in barrier function of the FAE. A few human markers have been suggested. One is Sialyl Lewis A Antigen, ${ }^{40}$ but we (unpublished observations) and others, ${ }^{7}$ have not been able to confirm this finding. Other suggested M-cell markers are Cathepsin $\mathrm{E}^{41}$ and $\beta$-1 integrin. ${ }^{42}$ Furthermore, it has been shown in experimental models that dendritic cells can extend their processes through the epithelial tight junctions and sample both pathogenic and nonpathogenic luminal microbes. ${ }^{43}$ Whether the dendritic cells are involved also in the sampling process in FAE is, however, not known. Nevertheless, our data support the notion of a high degree of bacterial-epithelial-immune cell interaction in the human FAE.

In conclusion, enhanced antigen and bacterial uptake, but similar paracellular permeability, suggest functional variations mainly of transcellular transport in the FAE. Our results show that human ileal FAE is functionally distinct from regular VE, making it more prone to interaction with, and transport of, antigens and bacteria. We have in this work established a reliable technique for functional studies of human ileal FAE. As there are critical species differences in FAE and M-cell biology, this opens up new possibilities to study interactions between luminal antigens and the mucosal immune system of the human gut. We can thereby increase our knowledge on oral vaccination, and gain essential information on the pathophysiology of human inflammatory diseases with relevance to the FAE, for example Crohn's disease.

\section{Acknowledgements}

We thank Dr Ping-Chang Yang, McMaster University, for help with parts of the electron microscopy studies, and Mrs Ylva Braaf and Mrs Eva Sjödahl for skilful technical assistance in the Ussing lab. This study was supported by The Broad Medical Research Program of the Eli and Edythe L. Broad Foundation, The Swedish Society for Medical Research and The Swedish Research Council.

\section{References}

1 Neutra MR, Mantis NJ, Kraehenbuhl JP. Collaboration of epithelial cells with organized mucosal lymphoid tissues. Nat Immunol 2001;2:1004-1009.

2 Gebert A. The role of $\mathrm{M}$ cells in the protection of mucosal membranes. Histochem Cell Biol 1997;108: $455-470$. 
3 Clark MA, Jepson MA. Intestinal M cells and their role in bacterial infection. Int J Med Microbiol 2003; 293:17-39.

4 Man AL, Prieto-Garcia ME, Nicoletti C. Improving M cell mediated transport across mucosal barriers: do certain bacteria hold the keys? Immunology 2004;113: 15-22.

5 Owen RL. Sequential uptake of horseradish peroxidase by lymphoid follicle epithelium of Peyer's patches in the normal unobstructed mouse intestine: an ultrastructural study. Gastroenterology 1977;72:440-451.

6 Gebert A, Rothkotter HJ, Pabst R. M cells in Peyer's patches of the intestine. Int Rev Cytol 1996;167: 91-159.

7 Wong NA, Herriot M, Rae F. An immunohistochemical study and review of potential markers of human intestinal M cells. Eur J Histochem 2003;47:143-150.

8 Velin AK, Ericson AC, Braaf Y, et al. Increased antigen and bacterial uptake in follicle associated epithelium induced by chronic psychological stress in rats. Gut 2004;53:494-500.

9 Owen RL, Pierce NF, Apple RT, et al. M cell transport of Vibrio cholerae from the intestinal lumen into Peyer's patches: a mechanism for antigen sampling and for microbial transepithelial migration. J Infect Dis 1986;153:1108-1118.

10 Van Kruiningen HJ, West AB, Freda BJ, et al. Distribution of Peyer's patches in the distal ileum. Inflamm Bowel Dis 2002;8:180-185.

11 Kerneis S, Bogdanova A, Kraehenbuhl JP, et al. Conversion by Peyer's patch lymphocytes of human enterocytes into $M$ cells that transport bacteria. Science 1997;277:949-952.

12 Schulte R, Kerneis S, Klinke S, et al. Translocation of Yersinia entrocolitica across reconstituted intestinal epithelial monolayers is triggered by Yersinia invasin binding to beta1 integrins apically expressed on M-like cells. Cell Microbiol 2000;2:173-185.

13 El Bahi S, Caliot E, Bens M, et al. Lymphoepithelial interactions trigger specific regulation of gene expression in the $M$ cell-containing follicle-associated epithelium of Peyer's patches. J Immunol 2002;168: 3713-3720.

14 Liang E, Kabcenell AK, Coleman JR, et al. Permeability measurement of macromolecules and assessment of mucosal antigen sampling using in vitro converted $\mathrm{M}$ cells. J Pharmacol Toxicol Meth 2001;46:93-101.

15 Roth-Walter F, Bohle B, Scholl I, et al. Targeting antigens to murine and human M-cells with Aleuria aurantia lectin-functionalized microparticles. Immunol Lett 2005;100:182-188.

16 Fotopoulos G, Harari A, Michetti P, et al. Transepithelial transport of HIV-1 by $\mathrm{M}$ cells is receptor-mediated. Proc Natl Acad Sci USA 2002;99:9410-9414.

17 Heppner FL, Christ AD, Klein MA, et al. Transepithelial prion transport by $M$ cells. Nat Med 2001;7: 976-977.

18 Gullberg E, Leonard M, Karlsson J, et al. Expression of specific markers and particle transport in a new human intestinal M-cell model. Biochem Biophys Res Commun 2000;279:808-813.

19 Grass GM, Sweetana SA. In vitro measurement of gastrointestinal tissue permeability using a new diffusion cell. Pharm Res 1988;5:372-376.

20 Soderholm JD, Hedman L, Artursson P, et al. Integrity and metabolism of human ileal mucosa in vitro in the Ussing chamber. Acta Physiol Scand 1998;162:47-56.
21 Karlsson J. Drug Absorption in Cell Culture Models of the Intestinal Epithelium [Dissertation]. Pharmaceuticals, Uppsala University: Sweden, 1995.

22 Wan CP, Park CS, Lau BH. A rapid and simple microfluorometric phagocytosis assay. J Immunol Meth 1993;162:1-7.

23 Maniak M. Macropinocytosis. In: Marsh M (ed). Endocytosis. Oxford University press: New York, 2001, pp 1-25.

24 Wadia JS, Stan RV, Dowdy SF. Transducible TAT-HA fusogenic peptide enhances escape of TAT-fusion proteins after lipid raft macropinocytosis. Nat Med 2004;10:310-315.

25 Apodaca G. Endocytic traffic in polarized epithelial cells: role of the actin and microtubule cytoskeleton. Traffic 2001;2:149-159.

26 Wallon C, Braaf Y, Wolving M, et al. Endoscopic biopsies in Ussing chambers evaluated for studies of macromolecular permeability in the human colon. Scand J Gastroenterol 2005;40:586-595.

27 Tavelin S, Grasjo J, Taipalensuu J, et al. Applications of epithelial cell culture in studies of drug transport. Methods Mol Biol 2002;188:233-272.

28 Kennedy DJ, Raldua D, Thwaites DT. Dual modes of 5-(N-ethyl-N-isopropyl)amiloride modulation of apical dipeptide uptake in the human small intestinal epithelial cell line Caco-2. Cell Mol Life Sci 2005;62:1621-1631.

29 West MA, Bretscher MS, Watts C. Distinct endocytotic pathways in epidermal growth factor-stimulated human carcinoma A431 cells. J Cell Biol 1989;109: 2731-2739.

30 Hewlett LJ, Prescott AR, Watts C. The coated pit and macropinocytic pathways serve distinct endosome populations. J Cell Biol 1994;124:689-703.

31 Green BT, Brown DR. Differential effects of clathrin and actin inhibitors on internalization of Escherichia coli and Salmonella choleraesuis in porcine jejunal Peyer's patches. Vet Microbiol 2006, in press [Epub ahead of print].

32 Apodaca G. Endocytic traffic in polarized epithelial cells: role of the actin and microtubule cytoskeleton. Traffic 2001;2:149-159.

33 Clark MA, Hirst BH. Expression of junction-associated proteins differentiates mouse intestinal $M$ cells from enterocytes. Histochem Cell Biol 2002;118: 137-147.

34 Tamagawa H, Takahashi I, Furuse M, et al. Characteristics of claudin expression in follicle-associated epithelium of Peyer's patches: preferential localization of claudin- 4 at the apex of the dome region. Lab Invest 2003;83:1045-1053.

35 Berkes J, Viswanathan VK, Savkovic SD, et al. Intestinal epithelial responses to enteric pathogens: effects on the tight junction barrier, ion transport, and inflammation. Gut 2003;52:439-451.

36 Zareie M, Riff J, Donato K, et al. Novel effects of the prototype translocating Escherichia coli, strain C25 on intestinal epithelial structure and barrier function. Cell Microbiol 2005;7:1782-1797.

37 Neutra MR, Mantis NJ, Frey A, et al. The composition and function of $\mathrm{M}$ cell apical membranes: implications for microbial pathogenesis. Semin Immunol 1999;11: 171-181.

38 Cuvelier CA, Quatacker J, Mielants H, et al. M-cells are damaged and increased in number in inflamed human ileal mucosa. Histopathology 1994;24:417-426. 
39 Kucharzik T, Lugering A, Lugering N, et al. Characterization of $\mathrm{M}$ cell development during indomethacininduced ileitis in rats. Aliment Pharmacol Ther 2000;14:247-256.

40 Giannasca PJ, Giannasca KT, Leichtner AM, et al. Human intestinal $M$ cells display the sialyl Lewis A antigen. Infect Immun 1999;67:946-953.

41 Finzi G, Cornaggia M, Capella C, et al. Cathepsin E in follicle associated epithelium of intestine and tonsils: localization to $\mathrm{M}$ cells and possible role in antigen processing. Histochemistry 1993;99: 201-211.

42 Hamzaoui N, Kerneis S, Caliot E, et al. Expression and distribution of beta1 integrins in in vitro-induced $\mathrm{M}$ cells: implications for Yersinia adhesion to Peyer's patch epithelium. Cell Microbiol 2004;6:817-828.

43 Rescigno M, Urbano M, Valzasina B, et al. Dendritic cells express tight junction proteins and penetrate gut epithelial monolayers to sample bacteria. Nat Immunol 2001;2:361-367. 